\title{
O DIREITO À ÁGUA E SAÚDE PÚBLICA
}

The right to water and public health

${ }^{1}$ Universidade de Coimbra. Coimbra, Portugal.

Correspondência:Wladimir António Ribeiro.E-mail: wladimir_ribeiro@manesco.com.br.

Recebido: 16/01/2018. 


\section{Introdução}

O “Tema em Debate” desta edição da Revista de Direito Sanitário trata do direito à água e saúde pública. São três artigos, os dois primeiros analisam a fluoretação da água e, o último, a gestão dos recursos hídricos. Como veremos, há um fio de Ariadne que os une: o tema da democracia, ou a política como mediadora dos conflitos sociais por meio do direito e de si mesma.

\section{I. Água e saúde: fluoretação e revogação da Lei Federal n. 6.050/1974}

Em seu trabalho, Zilbovicius, Aguiar e Narvai analisam as justificativas apresentadas pelos autores de dois projetos de lei, de iniciativa parlamentar, ambos com o objetivo de revogar a Lei Federal n. 6.050, de 24 de maio de 1974, que "dispõe sobre a fluoretação da água em sistemas de abastecimento quando existir estação de tratamento" e que prevê que "os projetos destinados à construção ou à ampliação de sistemas públicos de abastecimento de água, onde haja estação de tratamento, devem incluir previsões e planos relativos à fluoretação da água, de acordo com os requisitos e para os fins estabelecidos no regulamento desta Lei” (art. $1^{\circ}$, caput).

De maneira paciente, exaustiva e técnica, os autores demonstram que as “justificativas” dos projetos de lei em questão não apresentam qualquer espécie de fundamento técnico ou científico. No trabalho, uma sutil contradição: ora afirmam que seria "altamente recomendável que, antes de apresentar projetos de lei, os proponentes estudem o assunto", ora dizem que "eventuais deficiências [...] não resultam das dificuldades de assessoramento técnico científico, mas de posições [...] cujas motivações implicam a ocultação dos interesses subjacentes à iniciativa parlamentar". Tal lapso parece se dever ao excesso de elegância dos autores, extremamente vinculados ao espírito científico, resumido na máxima tacitiana sine ira et studio. Digamos aqui, por irresistível, o que ficou apenas sugerido ao nosso espírito: as iniciativas parlamentares submetidas ao escrutínio dos autores se enquadram perfeitamente no ambiente atual, de post-truth, inclusive no que esgrimem argumentos ad terrorem vazios de fundamento, mas capazes de incutir o medo, para atender a interesses sôfregos em permanecerem ocultos.

\section{A questão social da fluoretação das águas e a efetivação do direito à saúde}

O segundo artigo, de Sousa, Pinheiro, Araújo e Araújo, cuida também do tema da fluoretação, porém o analisando sob o ponto de vista não de uma mera obrigação do poder público, prevista em lei federal, mas de um direito subjetivo das populações, derivado de seu direito de ter acesso à água.

A Lei Nacional de Saneamento Básico (LNSB) - Lei n. 11.445, de 5 de janeiro de 2007 - reconheceu o direito de todos os ocupantes de domicílios ao serviço público de abastecimento de água potável (art. $\left.3^{\circ}, \mathrm{III}\right)$, que deve ser concretizado 
de forma progressiva e sem retrocessos (porém, respeitadas as situações de contingência), conforme previsto no plano de saneamento básico de cada Município (art. 19, caput, II).

Doutro lado, definir quais parâmetros as águas devem atender quando destinadas ao consumo humano é, nos termos constitucionais, papel do Sistema Único de Saúde (art. 200, VI, in fine), sendo que a água fornecida pelo serviço público de abastecimento de água, obrigatoriamente, deve atender a essas normas nacionais relativas à potabilidade (art. $9^{\circ}$, III, in fine, da LNSB). E as normas de potabilidade atuais - seja a Lei Federal n. 6.050/1974, seja a Portaria n. 2.914, de 11 de dezembro de 2011, do Ministério da Saúde, que dispõe sobre os parâmetros de potabilidade da água - preveem índices mínimos de flúor para considerar uma água como potável, vale dizer, como apropriada para o consumo humano.

A análise dos autores é profunda e, inclusive, perquire sobre o direito à saúde e seu regime jurídico, seja na ordem internacional, seja na ordem constitucional, além de demonstrar como a tecnologia de fluoretação é muito eficaz na redução de iniquidades. Uma das conclusões a que chegam é que falta eficácia, ou seja, que a administração pública, que deveria prover os serviços públicos de abastecimento de água potável, ora não os viabiliza, ora fornece água - por si, ou por seus contratados - que não é potável, porque ausente a fluoretação.

Pensando nas soluções possíveis, os autores, sem negar o aspecto político do problema, entendem que "a judicialização como medida de buscar uma efetivação da fluoretação pode ser bem fundamentada para o contexto brasileiro".

\section{Direito das águas - trajetória legal, conflitos e participação social}

O terceiro artigo, de autoria de Rocha, Khoury e Damasceno, seguiu interessante itinerário: apontou para a inovação que representa o novo marco legal da gestão de recursos hídricos e seus vários instrumentos, constatando que: "Cada um desses instrumentos possui uma finalidade própria e uma razão de existir, funcionando como peças de uma engrenagem; não é possível que um substitua o outro, e o funcionamento completo dessa engrenagem requer que todos estejam existindo e cumprindo sua função."1

Analisam e contextualizam, especialmente na realidade do semiáridoº, o funcionamento (ou o não funcionamento) de cada um desses instrumentos. $\mathrm{E}$ logo surgem os conflitos pelo acesso à água e suas tentativas de composição, quer

\footnotetext{
${ }^{1} \mathrm{O}$ trecho citado nos trouxe à lembrança a famosa lição de Canotilho, que se utiliza da metáfora da charneira para esclarecer a relação entre Estado Democrático e Estado de Direito. (CANOTILHO, José Joaquim Gomes. Estado de Direito. Lisboa: Editora Gradiva, 1999. p. 10-11).

${ }^{2}$ Com apoio em Malvezzi, em passagem que merece destaque, os autores demonstram que o prefixo "semi", aqui, faz toda a diferença. MALVEZZI, R. Semi-árido: uma visão holística. Brasília: Confea, 2007.
} 
mediante um direito que não alcança eficácia, quer pela força do poder econômico, quer na construção de espaços institucionais de diálogo.

O artigo, por tocar com muita propriedade um tema extremamente sensível, neste ponto adquiriu algo de profético, porque antecipou os graves conflitos recentes sobre o tema da gestão de recursos hídricos, como o de Correntina, Estado da Bahia: ante a violência da captação de água por uma empresa do agronegócio que, praticamente, consumia toda a água disponível, houve também a violenta reação da população, a seguir organizada na forma de protestos pacíficos.

O uso da violência - seja pela captação de água para além do razoável, negando um elemento vital para toda a restante população, seja pela primeira reação desta mesma população - gerou uma "suspensão do direito", ou tornou clara sua insuficiência para enfrentar uma situação da vida, com "os direitos" de cada lado procurando os mais diversos elementos de eficácia (mediante o aparelho repressivo do Estado, convocado para proteger o ato de outorga com aparência de direito direito realizado de forma parcial, incompleta -, ou por meio da ação política, que mobilizou a população da região, na defesa do direito a uma existência digna) ${ }^{3}$.

\section{Considerações finais}

De um lado, há um parlamento onde se apresentam, e reapresentam, propostas que, em última análise, prejudicam a saúde pública, para isso não se envergonhando de utilizar argumentos que infundem o medo, porém desprovidos de qualquer conteúdo de verdade ou, mais tecnicamente, desprovidos de fundamentos científicos. Deveriam a técnica e a ciência se sobrepor, em uma reedição da tecnocracia? Haveria a morte da democracia representativa, colonizada pelos grupos de interesse?

Doutro lado, a existência de um direito reconhecido e declarado que não encontra eficácia, configurando uma "promessa não cumprida" de acesso a serviços públicos de abastecimento de água potável (portanto, com níveis de flúor adequados). Deve o direito ingressar no seio da opinião pública, para se tornar visível e eficaz? Ou faltam meios repressivos - vale dizer, a violência exercida pelo Estado - para coibir a inobservância desse direito?

\footnotetext{
${ }^{3}$ No dia 7 de novembro de 2017, o governo federal divulgou uma proposta de medida provisória para alterar a lei de criação da Agência Nacional de Águas (ANA) e a LNSB. A proposta, ainda incipiente e eivada de muitos problemas técnicos, previa inclusive que, em situações de escassez hídrica, nas bacias integradas por rio federal, a gestão dos recursos hídricos de toda a bacia seria transferida para a União. Apesar de a proposta ser evidentemente inconstitucional, porque pretende desapropriar os Estados da gestão de bens reconhecidos a eles pelo texto do artigo 26 da Constituição Federal de 1988, demonstra que a situaçãolimite de crise hídrica e os conflitos derivados dela estão levando a que se proponham formas novas para se garantir eficácia aos instrumentos de gestão de recursos hídricos, num quase reconhecimento de que as formas atuais, onde prevalecem instâncias colegiadas e a construção de consensos, pelo menos nessas situações, são de baixa eficácia.
} 
Por fim, a suspensão do direito que leva a que os mais fortes ganhem o conflito, porque, sem a mediação do direito, é a força quem prevalece. Quem deve fazer valer o direito: o logos expresso em uma autoridade, novamente por meio de mecanismos repressivos, ou a construção de espaços sociais de consenso e legitimação? Ou seriam os dois caminhos, mas em qual correlação?

Para nós, a resposta está próxima do que enuncia Agamben, justamente quando analisa situações-limite do direito: "A política sofreu um eclipse duradouro porque se contaminou com o direito, concebendo-se, no melhor dos casos, como poder constituinte (isto é, violência que põe o direito), quando não se reduz simplesmente a poder negociar com o direito. Verdadeiramente política é, pelo contrário, só aquela ação que corta o nexo entre violência e direito"*.

Caro leitor, difícil realizar uma apresentação sem assumir o papel de spoiler. Mas, aqui, mesmo antecipando algum conteúdo, o nosso esforço foi o de apenas aguçar sua curiosidade, mostrando alguns dos desafios que lançam os artigos publicados a seguir.

\section{Referências}

AGAMBEN, Giorgio. Estado de excepção. Tradução de Miguel Freitas da Costa. Lisboa: Editorial 70, 2010.

CANOTILHO, José Joaquim Gomes. Estado de Direito. Lisboa: Editora Gradiva, 1999.

MALVEZZI, R. Semi-árido: uma visão holística. Brasília: Confea, 2007.

${ }^{4}$ AGAMBEN, Giorgio. Estado de excepção. Tradução de Miguel Freitas da Costa. Lisboa: Editorial 70, 2010. p. 132.

Wladimir António Ribeiro - Mestre em Ciências Jurídico-Políticas pela Universidade de Coimbra (Portugal); bacharel em Direito pela Universidade de São Paulo. Advogado. São Paulo/SP, Brasil. E-mail: wladimir_ribeiro@manesco.com.br. 